\title{
Extent of Academic Leaders' Practice for Wise Governance from Faculty Members' Perspective in Mu'tah University
}

\author{
Dr Hind khaled domuor \\ Noura Ali jadallah
}

\begin{abstract}
the study aimed to identify the extent of academic leaders' practice for wise governance from faculty members' perspective in Mu'tah University. The sample of the study was consisted of ( 323 ) faculty members whom were randomly selected from the study population which consisted of ( 556 ) faculty members at Mu'tah university. To achieve the goals of the study, the researchers developed the governance practice questionnaire of 30 items and checked it for reliability and consistency. Results indicated that the extent of academic leaders' practice for wise governance from faculty members' perspective in Mu'tah University came at high level on all items. Results also indicated no significant statistical differences in academic leaders' practice for wise governance that are attributed to gender or faculty variables. Finally, results indicated differences in the extent of academic leaders' practice for wise governance that are attributed to the variable of the academic position and these differences were in favor of co-professors. In light of the results, the study recommended with persistence in practicing wise governance by academic leaders in Mu'tah University.
\end{abstract}

Keywords : Wise Governance $\backslash$ Academic Leaders $\backslash$ Mu'tah University.

DOI: $10.7176 / \mathrm{JEP} / 10-2-01$

\section{Background :}

Educational institutions seek to construct aware leaderships that interact with changes with a scientific way , influence workers and reshape their behavior to the benefit of the institution and include workers in wise decision making process with a pattern that enables them to interact with these decisions effectively which in turn leads to achieving the goals for which these decisions are made and hence this offers benefit for both the institution and the workers alike.

Educational departments and directorates work on making available the mechanisms in order to create developments and changes that assist them to advance the educational institutions in all aspects by the accurate and continuous review for their behaviors and relationships with all national, regional and international levels. Hence, the significance of governance emerges to create a wise leadership in its behaviors, performance and decisions with a pattern that achieves quality and efficiency for the learning-teaching process and ensures that graduates possess a great deal of knowledge and high skills to be employed in work market. Based on what is mentioned above, governance is a future symbol for educational institutions, shapes students behavior, constructs their skills and values and shapes their future with a strong and firm manner ( Altaweel, 2006 ).

Wise governance is based on a group of elements that include : democracy, decentralization, dialogue, relations with the civil community, transparency, accountability, human rights and justice. Wise governance aims to achieve harmony and social justice via providing with the employees" minimum necessary requirements and needs which offer them a good level of life and also aims to achieve a level of competence and cooperation among individuals and institutions through a supportive social environment (Obeidat, 2001 ).

Alkayed ( 2003 ) confirmed the necessity of making available several ingredients in order for the government to adopt wise governance in institutions, these ingredients include :

- Enabling administrative and technical human sources at the local level by training and education and by developing the required skills.

- Developing the workers participation level in making work-related policies and decisions .

- Adopting new methods in administration and developing the institutional construct based on transparency and accountability.

- Wise governance requires a basic infrastructure for developing wealth and developing the existed institutions' abilities and potentials.

The importance of academic leaders lies in their efforts in facilitating the tasks of their administration which increases the vital role the educational institutions play in advancing the development and growth within community. This necessarily means that educational leaders at various levels have to possess particular skills that assist them in performing their appointed tasks with competency ( Nassir, 2012 ).

Education is the corner stone for the development of any nation and for advancing development and growth, and has a prominent significance in increasing and achieving all forms of development in addition to advancing the movement of progress. University has an eminent position within the educational system as it occupies the top of the educational hierarchy and due to this position, university is responsible not only for developing itself, but also the educational system as whole. The role of university education isn't limited to preparing and training 
human resources and staffs and creating leaderships, but also it includes developing the community and contributing in advancing the scientific research to serve the community issues and to resolve its problems ( Arrwili, 2009 ).

Governance has a great importance within universities due to the radical changes occurred to education recently. Fabric and Alexander ( 2008 ) indicated these changes as follows :

- The high social stresses on higher education institutions because of the increases in students' numbers which is related to the increases in the total population in turn.

- The emergence of new educational types offered by various local and international educational institutions.

- The emergence of open, rapid and distance education .

- The rapid scientific development and the cognitive increase which requires offering skilled graduates.

\section{Wise Governance Principles :}

Among the wise governance principles : clarity of goals, accountability, representing the main stockholders ( public base), clarity of the roles of the academic senate as an entity and for each member, circulation of leadership positions by elections and following agreed upon clear rules and procedures and declared for all ( Alzahrani, 2011 ). Obstacles Against Applying Universities' Governance :

Alfarra ( 2013 ) sees that applying governance within universities is conditioned by the followings :

- The prevalent culture among community : thinking patterns of universities' officials are related to the prevalent culture among community and these patterns of thinking are determined based on this culture.

- The general political climate : the country's policy plays a great role in framing the universities related policies.

- University regulations : university regulations may represent an obstacle against achieving universities strategic goals.

- University administration : the authoritarian administration may control all tasks and planned policies.

- Absence of faculty members from university life : through not participating in planning and making the university policies.

The importance of governance in universities comes from two basic issues : the 1 st is represented by the availability of various resources to finance universities so as to achieve their goals and activities while the 2nd issue is represented by the expense processes and exploiting resources wisely which enables offering the services required from the university administration ( Khoursheed and Yousof, 2013 ).

Henard and Mettarle ( 2008 ) conducted a study that aimed to focus on instruction principles, laws and regulations for practicing wise governance and how to distinguish between governance and quality standards. The researcher conducted an analytical and comparative studies through analyzing documents of higher education institutions in ( 31 ) country with the cooperation of the Organization for Economic Co-operation and Development. Results indicated that governance became a great stress tool to improve and facilitate quality in all higher education aspects.

Drboer , Huisman and Meister ( 2010 ) investigated the situations of governance field in three countries' universities ( Holland, Austria and the UK ) and compared the constitutions of their instructional offices regarding to which extent do accountability, autonomy, and transparency exist. Results indicated that among the modern elements for the attempts to reform the higher education sector in Europe are the efforts to create new frames for universities' governance and the instructional educational offices there are a part of the reform processes but although these offices are important, few members of which aware to their real task. Results also indicated that the potential fields for improvement and development in framing the current offices and their practices would be achieved only by applying governance and its principles accurately and by activating the internal and external control role within them.

Mok's study ( 2010 ) addressed universities in Singapore and to which extent they apply governance and its effects on changes occurred on university life. The study followed the analytical chronological approach during the period ( 2007-2009). Results indicated that most academics still face more stresses from university administrations rather than feeling individualism as they see that the country still unable to control universities and higher education.

Alzahrani ( 2011 ) conducted a study to identify the reality of applying governance within private universities in the KSA and to identify the job satisfaction and organizational loyalty extents among faculty members there. The study also aimed to identify the relationship nature among the variables of : specialty, gender, academic position, job position, real practical service, the reality of governance application, job satisfaction extent and organizational loyalty ). The study used an initial data questionnaire, the job satisfaction questionnaire and the reality of governance application questionnaire .The study followed the descriptive approach on a sample of (300) faculty members from Saudi private universities and colleges. Results indicated that Saudi private universities practice wise governance at a high level from faculty members' perspective , and also indicated significant statistical differences between participants" views about the reality of governance application in Saudi private universities and these differences are attributed to the variables of academic position 
and job position .

The study of Mungiu, Alina and Andra ( 2011 ) aimed to evaluate Roman public universities' governance and ( 43 ) universities were evaluated based on administrative integrity or academic integrity, democratic rule, academic governance and the proper finance for one academic year. Results indicated systematic problems in university life regulation and work performance within them and these problems are attributed to the failure in constructing accountability systems at the university level after the application of decentralization in university education to compete for improving the university general image and in turn to reform its practices.

Nassir Addin's study ( 2012 ) aimed to investigate the reality of governance application in the Middle East University from both faculty and administrative members' perspectives. The study sample included ( 113 ) participants ( 64 faculty members and 49 administrative members ). The study utilized questionnaire for data collection. Results indicated that the reality of governance application in the Middle East University from participants' perspectives was high. Results also indicated significant statistical differences at the level $\alpha \leq 0,05$ in the reality of governance application in the Middle East University based on the job position in favor of faculty members.

Alfarra ( 2013 ) conducted a study that aimed to high light the reality of governance in Palestinian universities and to identify the prominent challenges face Palestinian universities in strengthening governance there. The sample of the study was consisted of (202) participants and questionnaire was used for data collection. Results indicated that the universities visions and plans weren't continuously updated and there were no appropriate mechanisms to confirm their application, in addition, the accountability culture still low due to the lack for clear mechanisms that enables officials to offer appropriate clarifications for stockholders.

Sharaf's study ( 2015 ) aimed to identify the reality of governance systems' application in Palestinian universities in the West Bank and the challenges against this from faculty deans and heads of departments. The study also aimed to identify the influence of some variables' ( gender, job position, experience and university ) role in the application of governance systems and the challenges against this application. The sample of the study included ( 150 ) participants of faculty deans and heads of departments in the west bank's universities. The study utilized questionnaire for data collection. Results indicated a great response degree on the reality of governance application in Palestinian universities in the West Bank and a medium response degree on the challenges against this application. Finally . results indicated significant statistical differences at the level $\alpha \leq 0,05$, and these differences are attributed to the gender, job position and experience variables.

\section{Comments on Early Studies}

the above reviewed early studies addressed governance in various foreign and Arab universities with various samples and approaches. The current study is distinguished by that it addresses the extent of academic leaders' practice for wise governance from faculty members' perspective in Mu'tah University from faculty members' perspective and used questionnaire for data collection.

\section{Statement of the Problem}

The problem of this study is represented by identifying the extent of academic leaders' practice for wise governance from faculty members' perspective in Mu'tah University from faculty members' perspective and in answering the following research questions :

1- What is the extent of the extent of academic leaders' practice for wise governance from faculty members' perspective in Mu'tah University from faculty members' perspective ?

2- Are there significant statistical differences at the level $\alpha \leq 0.05$ in participants' responses on the extent of academic leaders' practice for wise governance from faculty members' perspective in Mu'tah University from faculty members' perspective based on the gender, academic position and faculty variables?

\section{Goals of the Study :}

This study aimed to :

* Determine the extent of academic leaders' practice for wise governance from faculty members' perspective in Mu'tah University from faculty members' perspective.

* Identify any existed statistical differences at the level $\alpha \leq 0.05$ in participants' responses on the extent of the extent of academic leaders' practice for wise governance from faculty members' perspective in Mu'tah University from faculty members' perspective .

\section{Significance of the study}

The significance of this study lies in that it seeks to identify the extent of the extent of academic leaders' practice for wise governance from faculty members' perspective in Mu'tah University from faculty members' perspective for the effective and influential role of wise governance in achieving the planned goals that would improve institutions' quality which in turn is reflected on the local community development. 


\section{Limitations of the Study :}

- Human limitations : faculty members in Mu'tah university.

- Objective limitations : wise governance practice extent.

- Spatial limitations : Mu'tah University.

- Time limitations : the academic year $2016 \backslash 2017$.

\section{Conventional and Procedural Definitions:}

* Governance : a group of laws, systems, regulations and decisions that aims to achieve quality and excellence in performance by selecting the appropriate and effective methods to achieve the institution's plans and goals ( Wylie, 2007 ).

Procedurally, governance is defined as the knowledge possessed by academic leaderships which is resulted from their response on the study tool that enables them to perform their administrative tasks.

* Academic Leaders : faculty deans and their deputies and academic departments' heads in Mu'tah University.

\section{Methodology and Procedures :}

this section offers a description of the study methodology, population, sample, the tool utilized with its reliability and consistency dimensions, variables, procedures and the followed analytical approaches to answer the research questions.

\section{Methodology :}

To achieve the study goals, the survey descriptive approach was used by distributing questionnaires, collecting them and then analyzing them using the appropriate statistical approaches to obtain the answers of the research questions.

\section{Study Population and Sample :}

The population of the study included ( 556 ) male and female faculty members from all scientific and humanistic faculties who hold Professor, Associate Professor, Assistant Professor positions in Mu'tah university for the academic year ( 2016 2017) from which a pilot sample of ( 30 ) members was selected to check for the reliability and consistency of the study tool while the original study sample was consisted of ( 323 ) male and female faculty members ( 161 male and 162 female members ) with a percentage of ( $58 \%$ ) as shown in table (1) below .

Table (1)

Sample distribution based on variables' levels

\begin{tabular}{|c|c|c|c|}
\hline Variable & Level & Number & Total \\
\hline \multirow[b]{2}{*}{ Gender } & Male & 161 & \multirow[t]{2}{*}{323} \\
\hline & Female & 162 & \\
\hline \multirow[t]{2}{*}{ Faculty } & Scientific & 246 & \multirow[t]{2}{*}{323} \\
\hline & Humanistic & 234 & \\
\hline \multirow{3}{*}{ Academic Position } & Professor & 71 & \multirow[t]{3}{*}{323} \\
\hline & Associate Professor & 179 & \\
\hline & Assistant Professor & 73 & \\
\hline
\end{tabular}

\section{Study Tool}

A questionnaire was developed based on the theoretical literature and early studies and was consisted of two parts : the $1^{\text {st }}$ included the respondents" personal variables ( gender, academic position and faculty ) and the 2nd included the 30 items that measure the extent of academic leaders' practice for wise governance, responses on the items were based on Likert five scale : 5= Very Great , 4= Great , 3= Medium , 2= Little and 1= Very Little.

\section{Tool Reliability}

To check for the reliability of the study tool, it was subscribed to a jury of 16exoerienced specialists in educational administration and evaluation and assessment to give their opinions and perceptions about the items' correctness, appropriateness and belonging to the dimensions they suppose to assess.

\section{Tool Consistency}

The tool was applied on a pilot sample from the study population and out of its original sample of ( 30 ) participants and consistency coefficients were calculated using the Cronbach Alpha as shown in table (2). 
Table (2)

Consistency coefficients using Cronbach Alpha for the governance dimensions' practice

\begin{tabular}{|l|l|}
\hline Dimension & CRONBACH Alpha \\
\hline Transparency & 0.89 \\
\hline Participation & 0.92 \\
\hline Accountability & 0.91 \\
\hline Scale as whole & 0.91 \\
\hline
\end{tabular}

From table (2) above, it is clear that coefficients are high and appropriate for the purpose of conducting this study.

\section{Variables :}

The study included the following variables :

- Independent secondary variables : gender ( malelfemale ), academic position ( Professor , Associate Professor, Assistant Professor ) and faculty ( scientific $\backslash$ humanistic ).

- Dependent variable : the extent of academic leaders' practice for wise governance from faculty members' perspective in Mu'tah University.

\section{Study Procedures :}

- Identifying the members of the study population in Mu'tah university for the academic year 2016\2017.

- Determining the participants in the study.

- Distributing the tool of the study with clarification for the goal of it and then it was completed by respondents.

- Analyzing and discussing the results and then concluding with recommendations in light of the results obtained.

\section{Statistical Treatment :}

To answer the research questions, the following statistical approaches were followed : Means, SDs, One-Way ANOVA, t-test and the Sheffe test to identify the variables' total effect.

\section{Results :}

Results related to the $1^{\text {st }}$ research question : What is the extent of the extent of academic leaders' practice for wise governance from faculty members' perspective in Mu'tah University from faculty members' perspective ?

To answer this question, means and SDs were calculated and ranks for the extent of academic leaders' practice for wise governance from faculty members' perspective in Mu'tah university were determined as shown in table (3).

Table (3)

Means, SDs and ranks for the extent of academic leaders' practice for wise governance in Mu'tah university

\begin{tabular}{|c|c|c|c|c|c|}
\hline No & Items & Mean & SD & Rank & $\begin{array}{c}\text { Practice } \\
\text { Degree }\end{array}$ \\
\hline 12 & $\begin{array}{l}\text { Academic leader includes university employees in giving opinions } \\
\text { which leads to the university development. }\end{array}$ & 4.46 & 0.76 & 1 & High \\
\hline 5 & $\begin{array}{l}\text { Academic leaders apply laws on all employees without } \\
\text { discrimination. }\end{array}$ & 4.37 & 0.82 & 3 & High \\
\hline 8 & The university continuously evaluates its goals in order to develop. & 4.37 & 0.80 & 3 & High \\
\hline 9 & $\begin{array}{l}\text { Workers-related procedures are implemented clearly ( hiring, } \\
\text { promotion, retirement..etc). }\end{array}$ & 4.37 & 0.80 & 3 & High \\
\hline 7 & Financial policy is clearly determined for all workers. & 4.35 & 0.79 & 8 & High \\
\hline 22 & Accountability contributes in determining the university needs. & 4.35 & 0.78 & 8 & High \\
\hline 24 & $\begin{array}{l}\text { Accountability rules are fairly applied on both individual and group } \\
\text { levels. }\end{array}$ & 4.34 & 0.82 & 10 & High \\
\hline 30 & $\begin{array}{l}\text { The university believes on the local community right in controlling } \\
\text { performance. }\end{array}$ & 4.33 & 0.84 & 11 & High \\
\hline 23 & Accountability is used to enhance worker's work. & 4.32 & 0.82 & 12 & High \\
\hline 10 & $\begin{array}{l}\text { Academic leaders adopt faculty members' views regarding direct- } \\
\text { concern issues. }\end{array}$ & 4.31 & 0.81 & 13 & High \\
\hline 29 & $\begin{array}{l}\text { Accountability offers a stronger relationship among academic } \\
\text { leaders and employees in the university. }\end{array}$ & 4.30 & 0.82 & 14 & High \\
\hline 21 & The administrator deals wisely with matters. & 4.28 & 0.82 & 15 & High \\
\hline
\end{tabular}




\begin{tabular}{|c|c|c|c|c|c|}
\hline No & Items & Mean & SD & Rank & $\begin{array}{l}\text { Practice } \\
\text { Degree }\end{array}$ \\
\hline 19 & $\begin{array}{l}\text { Academic leader includes faculty members in planning students' } \\
\text { circular activities. }\end{array}$ & 4.27 & 0.86 & 16 & High \\
\hline 28 & $\begin{array}{l}\text { Administrative decisions in the university are more rational due to } \\
\text { accountability. }\end{array}$ & 4.27 & 0.83 & 16 & High \\
\hline 1 & $\begin{array}{l}\text { Governance board in the university is constituted in a democratic } \\
\text { way with the participation of all workers. }\end{array}$ & 4.26 & 0.82 & 18 & High \\
\hline 13 & University-related decisions are made by the majority opinions. & 4.24 & 0.83 & 19 & High \\
\hline 18 & $\begin{array}{l}\text { Academic leaders work on encouraging dialogue with open } \\
\text { communication which contributes in goals' achievement. }\end{array}$ & 4.24 & 0.93 & 19 & High \\
\hline 20 & $\begin{array}{l}\text { Representatives of faculty members in the university participate in } \\
\text { drawing accountability rules. }\end{array}$ & 4.21 & 0.87 & 21 & High \\
\hline 27 & Accountability is used for facilitating workers' performance. & 4.20 & 0.86 & 22 & High \\
\hline 2 & Applied laws in the university are characterized by clarity. & 4.19 & 0.87 & 23 & High \\
\hline 11 & $\begin{array}{l}\text { Academic leaders follow the dialogue and discussion method to } \\
\text { obtain decisions via the governance board. }\end{array}$ & 4.19 & 0.87 & 23 & High \\
\hline 25 & $\begin{array}{l}\text { Accountability is used to check for the actual desire to workers' } \\
\text { commitment. }\end{array}$ & 4.19 & 0.91 & 23 & High \\
\hline 6 & $\begin{array}{l}\text { Academic leaderships support the principle of transparency in } \\
\text { information exchange for all beneficiaries. }\end{array}$ & 4.18 & 0.93 & 26 & High \\
\hline 26 & Accountability helps in reducing time and financial wastes. & 4.17 & 0.90 & 27 & High \\
\hline 14 & $\begin{array}{l}\text { Academic leaders work on facilitating cooperative work among the } \\
\text { university various units. }\end{array}$ & 4.16 & 0.90 & 28 & High \\
\hline 15 & $\begin{array}{l}\text { Academic leaders make available a system to receive suggestions } \\
\text { and recommendations from the university employees. }\end{array}$ & 4.12 & 0.87 & 29 & High \\
\hline 17 & Faculty members participate in drawing the university strategic plan. & 4.11 & 0.95 & 29 & High \\
\hline 16 & $\begin{array}{l}\text { Academic leaders draw the university developmental plans with the } \\
\text { participation of all related parties. }\end{array}$ & 4.03 & 0.93 & 29 & High \\
\hline 4 & $\begin{array}{l}\text { Faculty members are aware to their roles in order to achieve } \\
\text { governance. }\end{array}$ & 3.99 & 0.97 & 30 & High \\
\hline 3 & $\begin{array}{l}\text { The governance board role is clearly determined and identified in the } \\
\text { university regulations. }\end{array}$ & 3.86 & 1.02 & 30 & High \\
\hline & Total & 4.22 & 0.65 & & High \\
\hline
\end{tabular}

Table (3) above, indicates that the extent of the academic leaders' practice for wise governance in Mu'tah university was high as the mean was $(4,22)$ with an SD of (0.65) and all items came at high level and means averaged between $(4.46-3.86)$. first came the 12 th item " workers in the university participate and give their opinions which leads to develop the university work " with a mean of ( 4.46 ) and an SD of (0.76), second came the 5th item " academic leaders apply laws on all employees without discrimination " with a mean of (4.40) and an SD of ( 0.82). Before the last, came the 4th item " faculty members are aware for their tasks to achieve governance " with a mean of (3.99) and an SD of ( 0.97 ) and at last came the 3rd item " the role of governance board is clearly defined in university regulations " with a mean of (3.86) and an SD of (1.02).

Wise governance is beneficial for all workers in the university as it promotes and enhances powers through workers' participations in giving their opinions which leads to development of the university work and this leads academic leaders to force laws and regulations on all employees without discrimination which in turn develops respect among all workers and high lights transparency in treatment. This facilitates the university's evaluation continuous process for its programs to develop these programs and the university alike which allows the implementation of the workers-related procedures clearly such as hiring, promotion or retirement.

This result of the high practice for wise governance by academic leaders may be attributed to the reliability of the wise governance principles in Mu'tah university, and to the academic leaders' commitment to implement these principles without discrimination. This result may also be attributed to the university higher administration follow up for implementing the governance principles in all divisions at the university and the faculty members' awareness for their roles and tasks to achieve governance in addition to the governance board role in determining and identifying the university regulations clearly at last. This means that faculty members have no appropriate or mutual knowledge about academics" roles in practicing governance in all university divisions and departments, and this may attributed to that academic leaders fail to develop knowledge among faculty members and this confirmed in the last item as the university regulations are not enough clear for the rest workers in the university. This result is in agreement with that of Alzahrani ( 2011 ), Nassir Addin ( 2012 ) and Sharaf ( 2015 ). 
Results related to the $2^{\text {nd }}$ research question :Are there significant statistical differences at the level $\alpha \leq 0.05$ in participants' responses on the extent of academic leaders' practice for wise governance from faculty members' perspective in Mu'tah University from faculty members' perspective based on the gender, academic position and faculty variables?

This question was answered based on the variables it includes as follows :

* Gender variable : to identify any existed significant statistical differences at $\alpha \leq 0.05$ level between academic leaders' practice for wise governance that are attributed to faculty members' gender, means, SDs and the t-test for independent samples were calculated as shown in table (4).

Table (4)

Means, SDs and t-test for gender effect on the extent of academic leaders' practice for wise governance in Mu'tah university

Governance Practice

\begin{tabular}{|l|c|c|c|l|l|l|} 
Gender & Number & Mean & SD & t-value & $\begin{array}{l}\text { Freedom } \\
\text { scores }\end{array}$ & Sig \\
\hline Male & 161 & 4.23 & 0.619 & 0.477 & 321 & 0.634 \\
\cline { 1 - 4 } Female & 162 & 4.20 & 0.686 & & \multirow{2}{*}{0.621} \\
\hline
\end{tabular}

Results in table (4) indicate no significant statistical differences at the level $\alpha \leq 0.05$ in academic leaders' extent of practicing wise governance in Mu'tah university from faculty members' perspective as $t$ value was ( 0.477 ) with a significance of ( 0.634$)$.

Academic positions within a university such as faculty members are designed based on non-discrimination based on gender as male and female faculty members have the same rights and the sane tasks and duties. This result may be attributed to the feeling of justice among faculty members of both genders as transparency and justice are the bases of treatment within the university without any prejudice to a party than the other. This result is in agreement with that of Sharaf ( 2015 ).

* Academic position variable : to identify any existed significant statistical differences at $\alpha \leq 0.05$ level between academic leaders' practice for wise governance that are attributed to the academic position variable, means and SDs were calculated as shown in table (5).

Table (5)

Means and SDs for the extent of academic leaders' practice for wise governance based on the academic position variable in Mu'tah university

\begin{tabular}{|l|c|c|c|c|}
\hline \multirow{4}{*}{$\begin{array}{l}\text { Governance } \\
\text { Practice }\end{array}$} & Academic Position & Number & Mean & SD \\
\cline { 2 - 5 } & Professor & 71 & 4.04 & 0.82 \\
\cline { 2 - 5 } & Associate Professor & 179 & 4.27 & 0.61 \\
\cline { 2 - 5 } & Assistant Professor & 73 & 4.25 & 0.53 \\
\cline { 2 - 5 } & Total & 323 & 4.22 & 0.65 \\
\hline
\end{tabular}

Table (5) indicates statistical differences in means of academic leaders' practice for wise governance in Mu'tah university based on the academic position variable as those who hold an associate professor position had the highest mean of $(4,27)$ and those of professor position had the least mean of ( 4.04$)$. To determine the difference significance between means, the One-Way ANOVA was used as shown in table (6).

Table (6)

One-Way ANOVA to determine differences' significance for the effect of the academic position variable on academic leaders' practice for wise governance in Mu'tah university

\begin{tabular}{|c|c|c|c|c|c|c|}
\hline \multirow{4}{*}{ Governance Practice } & Source & Squares' sum & Freedom Scores & Squares' Mean & f-value & Sig \\
\cline { 2 - 7 } & Among Groups & 2.689 & 2 & 1.345 & 3.200 & 0.042 \\
\cline { 2 - 8 } & Within Groups & 134.467 & 320 & 0.420 & & \\
\cline { 2 - 8 } & Total & 137.156 & 322 & & & \\
\hline
\end{tabular}

Results in table (6) indicate significant statistical differences at the level $\alpha \leq 0.05$ in the extent of academic leaders' practice for wise governance in Mu'tah university and these differences are attributed to the variable of academic position as $t$ value was ( 3.200 ) at a level of $\alpha \leq 0.042$. To determine the attributions of differences, post-comparison Sheffe test was used as shown in table (7).

Table (7)

Post-comparisons Sheffe test to determine differences' significance for the academic position effect on applying governance

\begin{tabular}{|l|c|c|c|c|c|}
\multicolumn{9}{c|}{} & Mean & Professor & Associate Professor & Assistant Professor \\
\hline \multirow{3}{*}{ Governance Practice } & Professor & 4.04 & & & \\
\cline { 2 - 6 } & Associate Professor & 4.27 & $* .22$ & & \\
\cline { 2 - 7 } & Assistant Professor & 4.25 & .21 & .01 & \\
\hline
\end{tabular}

*Statistically significant at $\alpha \leq 0.05$ level 
Results in table (7) indicate a significant statistical difference at the level $\alpha \leq 0.05$ each of a professor and associate professor positions and this difference was in favor of associate professor position. This result indicates a difference in faculty members' response on the academic leaders questionnaire based on academic position and this may indicate that an associate professors' feeling about the extent of practice as high because of their higher experiences and their direct interaction with academic leaders and these associate professors also may have been in higher academic positions in the university hence they were more close to the university regulations and laws. This result is in agreement with the resuly of Alxahrani ( 2011 ) and the result of Nassir Addin ( 2012 ) but nit with that of Sharaf ( 2015 ).

* Faculty Variable : to identify any existed significant statistical differences at $\alpha \leq 0.05$ level between academic leaders' practice for wise governance that are attributed to the faculty variable ( scientific ) humanistic ), means, SDs and the t-test for independent samples were calculated as shown in table (8).

Table (8)

Means, SDs and the t-test for the effect of faculty type on the extent of academic leaders' practice for wise governance from faculty members in Mu'tah university

\begin{tabular}{|l|l|c|c|c|c|c|c|}
\hline Governance Practice & Faculty & Number & Mean & SD & t-value & Freedom Scores & Sig \\
\cline { 2 - 9 } & Scientific & 301 & 4.21 & 0.657 & \multirow{2}{*}{-0.584} & \multirow{2}{*}{321} & \multirow{2}{*}{0.560} \\
\cline { 2 - 8 } & Humanistic & 22 & 4.29 & 0.605 & & & \\
\hline
\end{tabular}

Table (8) indicates no significant statistical differences at the level $\alpha \leq 0.05$ in the extent of academic leaders' practice for wise governance from faculty members' perspective in Mu'tah university that are attributed to the faculty variable as t calculated value was ( 0.584$)$ at the level ( 0.560$)$. This result may be attributed to that laws and regulations in the university aren't fairly and equally applied on all faculties without discrimination and that faculty members in the university have equal rights and tasks regardless the faculty they teach in.

In light of the results of the study, it is recommended that the role of academic leaders in practicing wise governance in Mu'tah university must be emphasized in addition to increasing faculty members' awareness about regulations and laws and making available the appropriate mechanisms to spread this awareness among workers in the university.

\section{References}

Alkayed, Zuhair ( 2003 ) Governance : Issues and Applications. Cairo, The Arab Organization for A administrative Development.

Alfarra, Majid Mohammad ( 2013 ) Governance Challenges in [alestinian Higher Education Institutions : A Case study on Administrative and Economic Sciences Faculties in Gaza. A Research Subscribed for The Arab 3rd Conference for Education Quality Assurance. Azzaitounah University. Jordan.

Altaweel, Hani ( 2001 ) Educational Administration and Organizational Behavior. Ed2. Amman. Dar Wae'l. Jordan.

Altaweel, Hani ( 2006 ) Educational Administration-Concepts and Horizonz . Ed2. Amman. Dar Wae'l. Jordan.

Alzahrani, Khadijah ( 2011 ) Realty of Wise Governance Application in Saudi Private Universities and its Relationship with Faculty Members' Organizational Loyalty in these Universities. ( Unpublished PhD Thesis ). Um Alqura Iniversity. KSA

Drboer, H. ; Huisman, J.; Meister S.(2010). Supervision in Modern University Governance: Boards under Scrutiny. Studies in Higher Education, 35 (3) P 317-333.

Fabric and Alexander,2008, Governance and quality guidelines in Higher Education, OECD.

Henard, Fabric and Mitterle, Alexander (2008). Governance and Quality in Higher Education Program on inistitutional management in Higher education France; OECD

Hyman, Kareem ,D. .(2005). Leadership, University of North Carolina North Carolina, US, PP. 1-37,

Khoursheed, M and Yousuf, M ( 2013 ) Universities Governance and Education and Scientific Research Enhancement in Egypt. Alexandria Library. Egypt.

Mok, Ka Ho.(2010). When State Centralism Meets Neo-Liberalism "Managing University Governance Change In Singapore and Malaysia" Higher Education- The World Bank : Trends Developing Economic, Africa Region Human Development, Washinghton, 2008, 60(4), 419-440.

Mungiu, P. ; Alina, D. ; Andra, E.(2011). Civil Society and Control of Corruption "Assessing Governance of Romanian Puplic Universities" International Journal of Educational Development, 31 (5) p526-554.

Nassir Addin, Ya'qoub ( 2012 ) Reality of Governance Application in the Middle East University from Administrative Staff and Faculty Members' Perspective. ( Unpublished M.A Thesis ). Middle East University. Amman . Jordan .

Obiedat, Zaha' Addin ( 2001 ) Educational Leadership and Administration in Islam. Amman. Dar Albaiariq. 
Jordan.

Sharaf,Hana' ( 2015 ) Reality of Governance Application and the Obstacles Against this in Palestinian Universities from Faculty deans and Departments' Heads in the West Bank. ( Unpublished M.A Thesis ). Alnajah National University, Palestine.

Wylie, Cathy (2007). School Governance in New Zealand- How is it working, New Zealand Council for Education Research, wellington, New Zealand. 